\title{
Effects of algicide on the growth of Microcystis flos-aquae and adsorption capacity to heavy metals
}

\author{
P. Y. Guo $\cdot$ Y. Liu $\cdot$ X. Wen • S. F. Chen
}

Received: 18 October 2013/Revised: 25 March 2014/Accepted: 2 June 2014/Published online: 23 July 2014

(C) Islamic Azad University (IAU) 2014

\begin{abstract}
In this paper, the effects of salicylic acid (SA) algicide carried by cross-linked chitosan on the inhibition of Microcystis flos-aquae and the removal ability of heavy metals $\mathrm{Pb}$ and $\mathrm{Ni}$ in compound polluted water were studied. The results showed that the algicide had significant inhibitory effects on Microcystis flos-aquae: when the concentrations were 550 and $700 \mathrm{mg} \mathrm{L}^{-1}$, the inhibition time was up to 13 days or more, and the inhibition rate was as high as $99 \%$. The algicide exhibited strong adsorption capacity to heavy metals $\mathrm{Pb}$ and $\mathrm{Ni}$. The adsorption rates of the algicide at concentrations of 400 and $550 \mathrm{mg} \mathrm{L}^{-1}$ on $\mathrm{Ni}$ and $\mathrm{Pb}$ were 61 and $64.9 \%, 71.2$ and $72.5 \%$ at 13 days, respectively. The algicide allows a slow release of SA and long-term inhibition of algae and has better adsorption capacity on heavy metals, thus providing a method for the effective control of eutrophication and combined heavy metal pollution in water.
\end{abstract}

Keywords Algicide - Heavy metals - Adsorption capacity · Microcystis flos-aquae · Cross-linked chitosan · Salicylic acid

P. Y. Guo $(\bowtie) \cdot$ Y. Liu $\cdot$ X. Wen · S. F. Chen

Department of Environmental Science and Engineering, College of Chemical Engineering, Huaqiao University, Xiamen 361021, Fujian, China

e-mail: peiyongguo@126.com

P. Y. Guo · Y. Liu

Institute of Environmental and Resources Technology, Huaqiao University, Xiamen 361021, Fujian, China

\section{Introduction}

With the development of modern agriculture and industry, water eutrophication problems have become increasingly prominent and are often accompanied by heavy metal pollution (Nikulina and Dullo 2009). Eutrophication problems induce the outbreak of algal bloom in water. Adsorption of water bloom algae causes accumulation of heavy metals with food chains and induces biological amplification, eventually resulting in serious toxicity to humans and animals (Jiang et al. 2012). Therefore, the inhibition of water bloom algae growth and removal of heavy metals are among the topics which currently require solving. In studies regarding a number of water eutrophication treating and combined heavy metal pollutions, it has been shown that using ecological security of allelopathy can effectively inhibit the growth of algae (Kovacik et al. 2010; Vidhyavathi and Sarada 2011), such as the allelopathic substance salicylic acid (SA), which exists extensively in the higher plants (Haddadchi and Gerivani 2009; You et al. 2011). SA has been separated and its inhibitory effects on algae have been investigated by researchers around the world ( $\mathrm{Li}$ et al. 2010). It has been discovered that SA can effectively control the growth of water bloom algae. However, during the direct addition of allelochemicals, there are the problems of local concentration being too high and continuous algae inhibition time being too short. Therefore, developing algicides with slow release functions to control the growth of bloom algae in water has broad prospects. Chitosan is one of the potential environment friendly-type adsorption materials in environment fields. Chitosan has a pore structure, and there are active functional groups of hydroxyl and amino in its molecules. Chitosan also has 
strong coordination ability to phenols, acids and heavy metals (Bailey et al. 1999; Kumar 2000; Yang et al. 2008; Imran et al. 2012). However, due to chitosan's shortcomings of easy loss, low mechanical strength and lack of regeneration ability, the application of chitosan is quite restricted (Zhen et al. 2011). Therefore, many scholars have begun to improve adsorbent chitosan with a clear aim (Wu et al. 2010), in which a cross-linking method is used as a simple and effective way to improve the structure stability of chitosan materials. Furthermore, some cross-linking methods can improve the adsorption capacity of chitosan on phenolic acids (Xin et al. 2009) and heavy metals (Jeon and Park 2005; Fan and Xu 2011; Yang et al. 2011; Kocak et al. 2012). In the present study, the effects of salicylic acid algicide carried by cross-linked chitosan on the slow release of SA and long-term inhibition of algae were further investigated, and the adsorption capacity of the cross-linked chitosan in the algicide on heavy metals was analyzed. The results provide a method for the effective control of eutrophication and combined heavy metal pollution in water.

\section{Materials and methods}

\section{Experimental materials}

Microcystis flos-aquae (FACHB-1028) was the water bloom algae species used in this study, which is capable of releasing algal toxins. The Microcystis flos-aquae (FACHB-1028) was purchased from the Freshwater Algae Culture Collection, Wuhan Aquatic Research Institute of Chinese Academy of Sciences. The specified culture medium BG11 was used in all of the experiments. Before the experiments, algae at the logarithmic phase were seeded into a 1-L conical flask containing a $400 \mathrm{~mL}$ newly prepared culture medium; then, the algae were cultured. When the density of the algae cells reached the logarithmic growth phase, they were seeded into a $100-\mathrm{mL}$ empty sterilized conical flask. After culturing for 1 day for stability, the algae were used for the follow-up experiments. The culture temperature was $25 \pm 1{ }^{\circ} \mathrm{C}$. The light-dark ratio was $12: 12 \mathrm{~h}$. The light intensity was $50 \mu \mathrm{mol}$ photons $\mathrm{m}^{-2} \mathrm{~s}^{-1}$. The algae cells were shaken three times per day. The positions of algae cells were adjusted randomly, so that the luminous flux in each bottle was consistent with each other to reduce accidental errors.

Chitosan with a deacetylation degree of $>80 \%$ was purchased from Sinopharm Chemical Reagent Co., Ltd. Analytically pure SA was purchased from Xilong Chemical Industry. Lead standard solution and nickel standard solution were purchased from Sinopharm Chemical Reagent Co., Ltd.

About $6.2 \mathrm{~g}$ of chitosan was weighed and dissolved in a $60 \mathrm{~mL}$ phosphate buffer with $\mathrm{pH}=8.0$. After stirring, $18 \mathrm{~mL}$ of glutaraldehyde was added to the solution. Then continuous stirring reaction and filtration were conducted, and water was used for washing. Finally, fine granular cross-linked chitosan was produced. The adsorption effects of chitosan on SA were investigated under single factor conditions of the initial concentration of SA solution, initial usage dose of cross-linked chitosan and temperature, based on which the orthogonal test was designed. The adsorption capacity of the crosslinked chitosan for SA was used as the response index to conduct sequencing of factor importance to determine the optimal combination of relatively high adsorption. The cross-linked chitosan was used to adsorb SA under the optimal conditions. After filtration, it was vacuumdried for $24 \mathrm{~h}$. The algicide was then synthesized. To prevent the autooxidation of the SA, the solutions in the experiments were all infused with nitrogen to conduct oxygen exhausting, and constant temperature shock synthesis was conducted under sealing conditions. The obtained optimal combination of the cross-linked chitosan dosage was $0.05 \mathrm{~g} / 20 \mathrm{~mL}$, which is within the range of the experiment, with the adsorption capacity as the response indicator. The temperature was $65{ }^{\circ} \mathrm{C}$. The initial concentration of SA was $1,000 \mathrm{mg} \mathrm{L}^{-1}$. Finally, algicide was obtained with the adsorption ratio of SA, and the cross-linked chitosan was $254.13 \mathrm{mg} \mathrm{g}^{-1}$.

Experimental methods

\section{Desorption of algicide in water for SA}

To investigate the release efficiency of algicide in water, $15,20,25,32,40,55$ and $70 \mathrm{mg}$ denominations of algicide were weighed and mixed into $100 \mathrm{~mL}$ of water, respectively. After resting at $25{ }^{\circ} \mathrm{C}$, supernatants were drawn in $0.2,0.5,1,3,10,24$ and $48 \mathrm{~h}$ and filtered with $0.45-\mu \mathrm{m}$ filter membranes, respectively. The absorbance was then measured by ultraviolet spectrophotometer to calculate the relative concentration of SA to explore desorption of SA under different algicide-adding conditions.

Effects of cross-linked chitosan, SA and algicide on growth of Microcystis flos-aquae

According to the proportion of the adsorbed SA by the cross-linked chitosan in algicide, the adding proportion of cross-linked chitosan/SA/algicide was set as 4:1:5. In the experiments, the corresponding weight materials were 
directly added into $100 \mathrm{~mL}$ of Microcystis flos-aquae solution in logarithmic phase (the content of chlorophyll a was approximately $1,000 \mu \mathrm{g} \mathrm{L}^{-1}$, and algal density was approximately $5 \times 10^{5}-6 \times 10^{5}$ cells $\mathrm{mL}^{-1}$ ). In the group treated with cross-linked chitosan, the final concentrations were set as $120,160,200,320,440$ and $560 \mathrm{mg} \mathrm{L}^{-1}$, respectively. In the group treated with $\mathrm{SA}$, the final concentrations were set as $30,40,50,80,110$ and $140 \mathrm{mg} \mathrm{L}^{-1}$, respectively. In the group treated with algicide, the final concentrations were set as 150,200, 250, 400, 550 and $700 \mathrm{mg} \mathrm{L}^{-1}$, respectively. In the refinement-adding group, the final concentrations of algicide were set as 60,100 and $320 \mathrm{mg} \mathrm{L}^{-1}$, respectively. The control group was CK. Three parallel samples were set in each group. The content of chlorophyll a was measured every second day.

The content of chlorophyll a was determined by a PhytoPAM Phytoplankton Analyzer. The measuring method was as described by Heinz (2003). Furthermore, algal cell density was measured by microscopic methods using the blood cellcounting chamber. The content of chlorophyll a was measured to obtain the relationships between Microcystis flosaquae cell density and chlorophyll a content in the algae solution. The correlation between the two was shown to be high; thus, it was concluded that determining the chlorophyll a content at regular times could reflect the algal growth.

\section{Research on algicide adsorption capacity to heavy metals}

According to the antialgal effect of algicide, 400 and $550 \mathrm{mg} \mathrm{L}^{-1}$ concentrations of algicides were selected to investigate the heavy metal sorption capacity. In order to study the removal capacity and adsorption capacity for algicide for the low concentration of heavy metal ions, $100 \mathrm{~mL}$ heavy metal $\left(\mathrm{Pb}^{2+}, \mathrm{Ni}^{2+}\right)$ solutions with initial concentrations of $1,2,3$ and $6 \mathrm{mg} \mathrm{L}^{-1}$, and 50, 100, 150, 200 and $250 \mathrm{mg} \mathrm{L}^{-1}$ were placed in 250 -mL conical flasks, respectively. Either 40 or $55 \mathrm{mg}$ of algicide was added into the conical flasks. After shaking at constant temperature for $4 \mathrm{~h}\left(25^{\circ} \mathrm{C}, 200 \mathrm{r} \mathrm{min}^{-1}\right)$ in the constant oscillation box, the supernatants were obtained and filtrated with a $0.45-\mu \mathrm{m}$ filter membrane. The heavy metal ion concentration in the solution was measured in the flame atomic absorption spectrophotometer. Finally, the adsorption rate and adsorption ratio were calculated.

\section{Heavy metal removal capacity of algicide in algae solution}

According to the inhibition effect of algicide on algae, the algicide treatment group with 400 and $550 \mathrm{mg} \mathrm{L}^{-1}$ algicide and the CK control group (100 mL Microcystis flos-aquae solution in the logarithmic phase, and the content of chlorophyll a was approximately $1,000 \mu \mathrm{g} \mathrm{L}^{-1}$ ) were added into the corresponding heavy metals $\mathrm{Pb}$ and $\mathrm{Ni}$ standard solutions, and the set final concentration was $1 \mathrm{mg} \mathrm{L}^{-1}$. The group without any heavy metal was used as a blank control. Chlorophyll $a$ contents were measured at 1, 3, 5, 7, 10 and 13 days. At the same time, some algae liquid was filtered by a $0.45-\mu \mathrm{m}$ filter membrane. The concentrations of the heavy metals were examined by flame atomic absorption spectrometry detection, and the adsorption rates were calculated.

\section{Data analysis methods}

Calculating algae inhibition rate The inhibition rate $(\%)=$ (chlorophyll content in the control group $\left(\mathrm{g} \mathrm{L}^{-1}\right)$ - the content of chlorophyll in the treated group $\left(\mathrm{g} \mathrm{L}^{-1}\right) /$ chlorophyll content in the control group $\left.\left(\mathrm{g} \mathrm{L}^{-1}\right)\right) \times 100$

Isothermal adsorption model of algicide to heavy metals The Langmuir isotherm adsorption model and Freundlich isotherm adsorption model are shown below:

$\frac{C_{e}}{Q_{e}}=\frac{1}{Q_{\max }} C_{e}+\frac{1}{Q_{\max } b}$

$Q_{e}=K C_{e}^{1 / n}$

In the formula, $Q_{\max }$ is the maximum adsorption capacity of algicide $\left(\mathrm{mg} \mathrm{g}^{-1}\right) ; Q_{\mathrm{e}}$ is the adsorption amount of algicide $\left(\mathrm{mg} \mathrm{g}^{-1}\right)$ when adsorption equilibrium is reached; $C_{\mathrm{e}}$ is the concentration of heavy metal ion when adsorption equilibrium is reached $\left(\mathrm{mg} \mathrm{L}^{-1}\right)$; and the parameter $b \quad\left(\mathrm{~L} \mathrm{mg}^{-1}\right)$ characterizes the affinity of adsorption sites on the surface of adsorption materials to the heavy metal ions. The larger the $b$ value is, the more affinity of adsorption sites on the surface of adsorption materials to the heavy metal ions there are. $K$ is a measure of adsorption capacity, reflecting the adsorption amount.

Data processing The data were analyzed by SPSS 18.0 software. Origin 8.0 was used in drawing the figures. The chlorophyll a content was analyzed by using repeated measure variance analysis. 


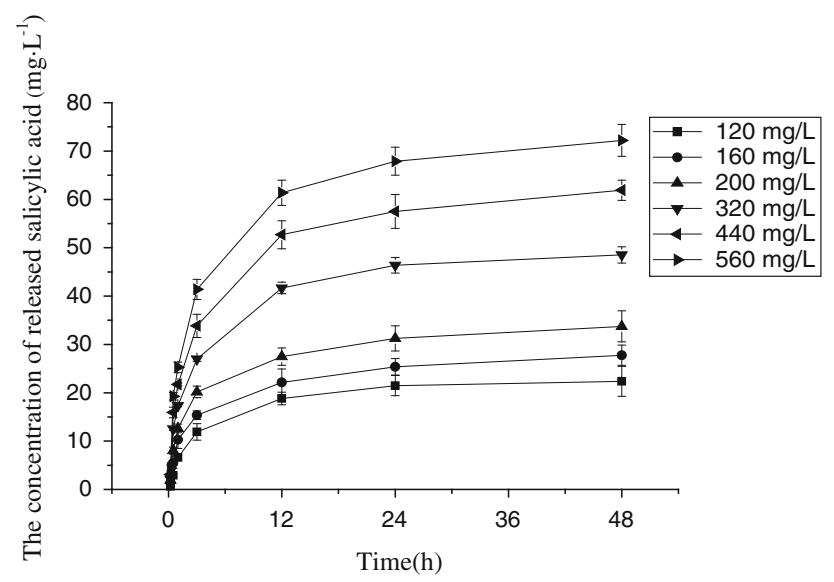

Fig. 1 Effects of dosage of SA algicide carried by cross-linked chitosan on desorption

\section{Results and discussion}

Desorption experimental results of algicide in water to SA

The effects of different algicide dosages on the release concentration of SA are demonstrated in Fig. 1. There are many pores in chitosan molecules which can absorb SA directly ( $\mathrm{Ji}$ et al. 2011). When the added dosages of algicide were $15,20,25,32,40,55$ and $70 \mathrm{mg}$, the increasing trend of the release concentration in the initial adding stage was quite fast, but it became a smooth trend at $12 \mathrm{~h}$. The release rates at $48 \mathrm{~h}$ were 74, 69, 67, 60, 56 and $51 \%$, respectively. With the increase adding weight of algicide, the release concentration of SA increased gradually, and the release rate exhibited a decreasing trend, indicating that the dissolved SA in the solutions affected the release of $\mathrm{SA}$ in the algicide. The higher concentration of the solution was, the lower the desorption ability was. When the adsorption and desorption reached a dynamic equilibrium, the concentration of SA stabilized. At the same time, autooxidation of SA occurred in the solutions, and concentration of SA decreased. Algicide would release a part of SA to add SA concentration in solutions, so as to achieve a new equilibrium. In addition, the release time was long enough for its uniform distribution after adding algicide into water, which would not cause high local concentration of algicide.

Effects of cross-linked chitosan, SA and algicide on growth of Microcystis flos-aquae

Effects of cross-linked Chitosan on Microcystis flos-aquae are shown in Fig. 2a, b. There was no significant difference of the content of chlorophyll a between the treated group and control group $(P>0.05)$. Furthermore, when different weights of cross-linked chitosan were added to the algae solutions, the algae inhibition rate fluctuated in $10 \%$, indicating that the cross-linked chitosan showed no evident effects on the growth of algae, and there was no correlation between the dosage of cross-linked chitosan and algae growth.

Effects of SA on Microcystis flos-aquae are demonstrated in Fig. 2c, d. The inhibitory effect increased with the increased SA concentration. When the usage concentrations of algicide were 30,40 and $50 \mathrm{mg} \mathrm{L}^{-1}$, then the inhibition rate fluctuated in the range of $40 \%$, and the inhibitory effect was not significant $(P>0.05)$. When the usage was $80 \mathrm{mg} \mathrm{L}^{-1}$, the inhibition rate could reach up to $80 \%$, and the inhibition on the growth of Microcystis flosaquae was dramatic $(P<0.05)$. When the usages were 110 and $140 \mathrm{mg} \mathrm{L}^{-1}$, the inhibition rate could reach up to $99 \%$, and the inhibition on the growth of Microcystis flosaquae was extremely significant $(P<0.01)$. The SA used in the present study consisted of phenolic allelochemicals. The mechanism of phenolic acids allelopathic inhibition may be involved in the production of free radicals and increased lipid peroxidation, thereby resulting in the destruction of membrane structures and impaired cell functions (Zhang et al. 2007).

The inhibitory effects of algicide on Microcystis flosaquae are illustrated in Fig. 2e, f. There was no significant difference in the contents of chlorophyll a when the added concentrations of algicide were 60, 100, 150, 200, 250 and $320 \mathrm{mg} \mathrm{L}^{-1}$, which may be due to the fact that the low concentration of the released SA was induced by adding algicide at the above concentrations, and the concentrations did not reach the threshold concentration affecting the synthesis of chlorophyll a. When the algicide concentration was $400 \mathrm{mg} \mathrm{L}^{-1}$, the inhibition rate at 7 days could reach $90 \%$, and the inhibition rate remained at 92-94\% when the time continued to the 13th day; when the algicide concentration was $550 \mathrm{mg} \mathrm{L}^{-1}$, the inhibition rate at 4 days could exceed $95 \%$, and the inhibition rate was as near as $100 \%$ after an additional 2 days, which could be continued to 13 days; and when the algicide concentration was $700 \mathrm{mg} \mathrm{L}^{-1}$, the inhibition rate at 1 days could reach above $95 \%$, and the inhibition rate was near $100 \%$ after an additional 3 days, which could be continued to 13 days. The above results suggest that longterm strong inhibition effects could be achieved when the added concentration of SA algicide carried by cross-linked chitosan is greater than $400 \mathrm{mg} \mathrm{L}^{-1}$. A large amount of hydroxyls and amino groups in chitosan can also produce chemical bonds by interacting with SA (Wei et al. 2010). The binding sites of SA and chitosan are located at the amido bond formed by the carboxylic acid group of SA 

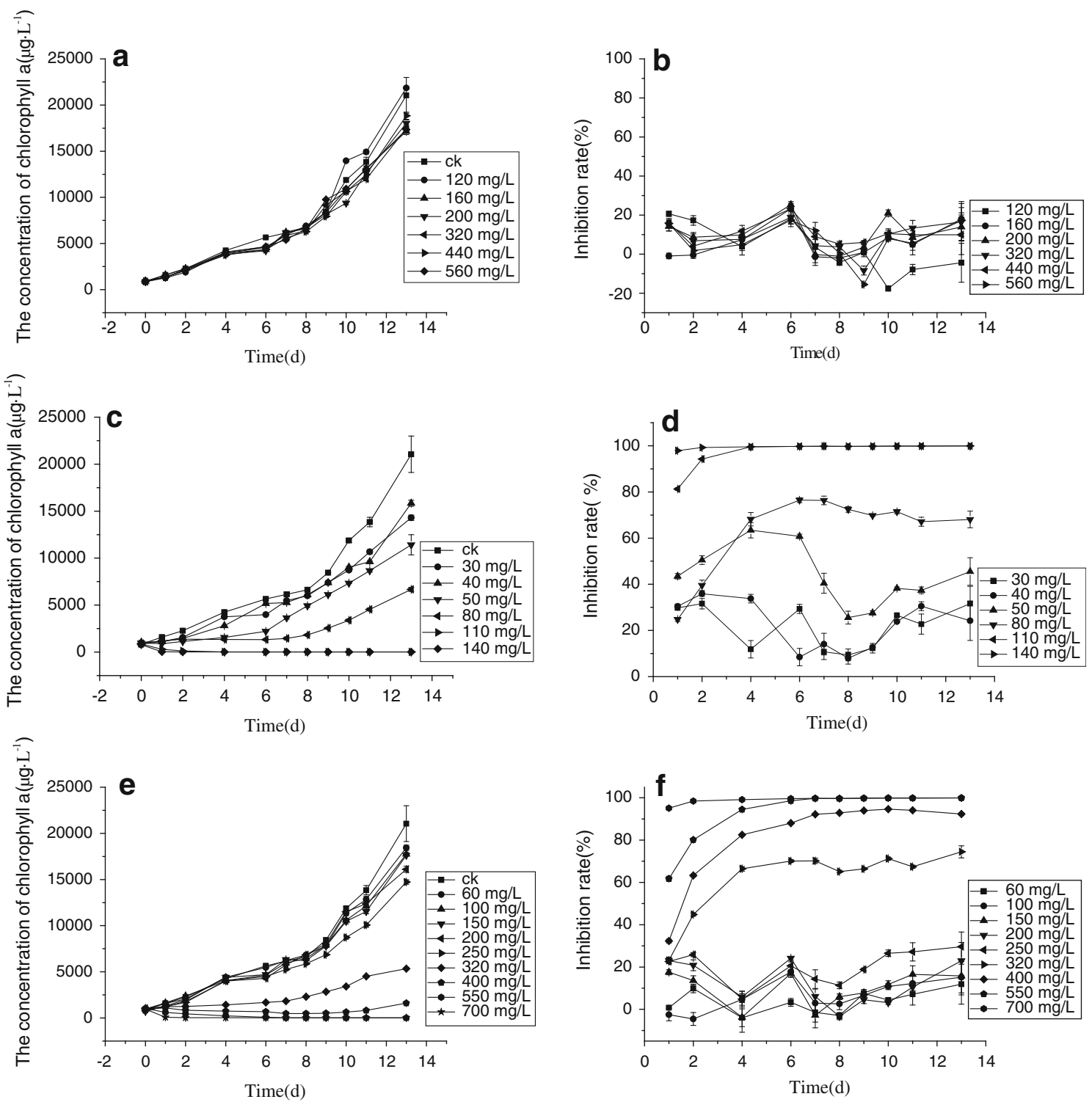

Fig. 2 Effects of CTS $(\mathbf{a}, \mathbf{b})$, SA (c, d) and CTS-SA $(\mathbf{e}, \mathbf{f})$ on the growth of Microcystis flos-aquae

and amino group of chitosan, or the ester bond formed by carboxylic acid group of SA and hydroxyl of chitosan. This combination is not easy to release, and the algicide can release the SA slowly, thus supplementing the consumption or autooxidation of SA, thereby achieving the purpose of long-term inhibition of algae. This is different from the results of the study performed by Chang et al. (2014), who proposed to remove Microcystis aeruginosa and microcystin-LR using nanosilicate platelet (NSP) derived from natural clay mineral; 100 and $500 \mathrm{ppm}$ dosages of NSP achieved 87.7 and $89.5 \%$ inhibition of Microcystis aeruginosa cell concentration level $(1.66 \times$
$10^{6}$ ) within $24 \mathrm{~h}$. Chlorophyll is the main pigment of photosynthesis. The destruction and degradation of chlorophyll will lead directly to reduced photosynthesis efficiency (Hou et al. 2012), and phenolic allelochemicals will affect the cyanobacterial photosystem II phycobiliproteins center (Wu et al. 2008), thus inhibiting the normal physiological function of algae. However, after SA is released into the algae liquid by algicide, the SA may be degraded by the resistance substances produced by the algae cells, or the SA may be absorbed and metabolized by algae cells as carbon sources. With the prolonged culture time, the concentration of SA in the medium will gradually decline. 

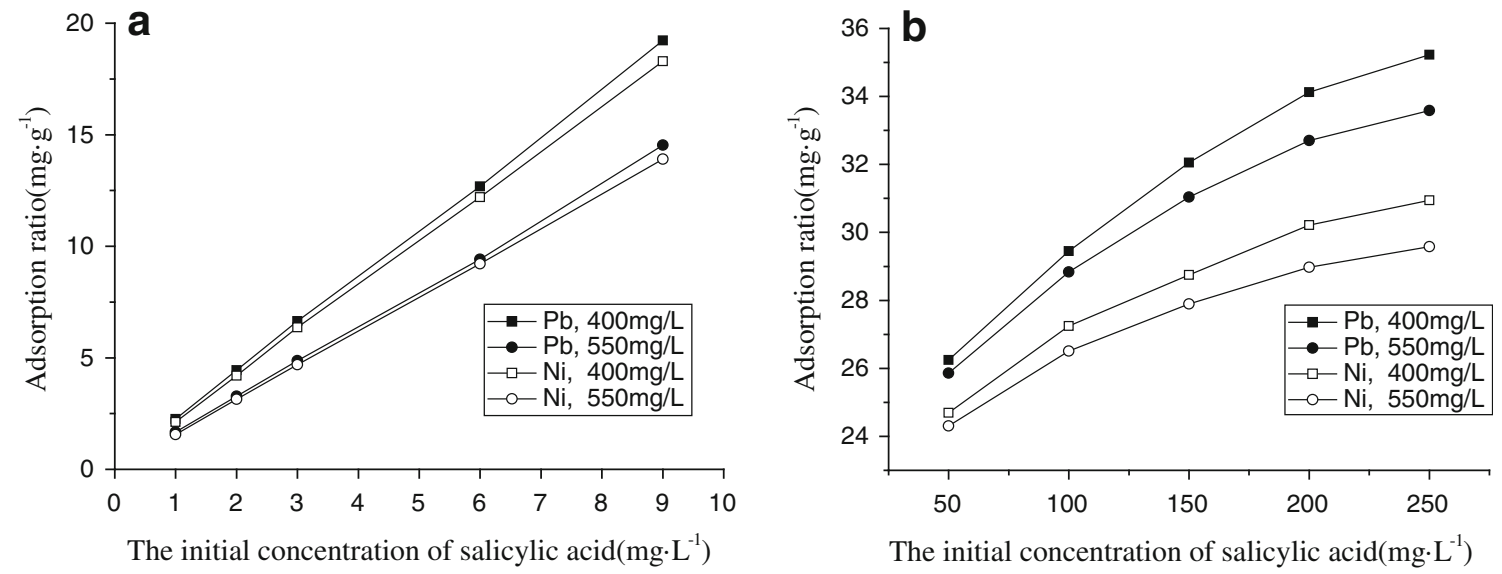

Fig. 3 Adsorption capacities of algaecides for low concentration (a) and high concentration (b) of heavy metals $\mathrm{Ni}$ and $\mathrm{Pb}$

When the concentration of SA reduced to a certain concentration which could not inhibit algae cell growth effectively, the inhibition rate was decreased (Poulson et al. 2010; Jiang et al. 2010).

\section{Adsorption capacity of algicide to heavy metals}

In the present experiment, the adsorption capacity of algicide to low concentration of heavy metals was explored, with the maximum adsorption capacity and adsorption difficulty degree as supplements. The removal ability of algicide to low concentration of heavy metal ions is shown in Fig. 3a. It is observed that the total quantity of heavy metals could be absorbed by algicide in water was small under low concentrations of heavy metals. The adsorption rate could reach $80-90 \%$. The adsorption ratio was mainly affected by the adding quantity. The adsorption rate of $400 \mathrm{mg} \mathrm{L}^{-1}$ algicide was clearly higher than that of $550 \mathrm{mg} \mathrm{L}^{-1}$ algicide. The adsorption rate of $\mathrm{Pb}$ by algicide was slightly higher than that of $\mathrm{Ni}$ when the adding amount was the same. The adsorption capacity of algicide to heavy metals is illustrated in Fig. 3b. The adsorption rate was between 5 and $30 \%$ when the concentrations of heavy metals were higher, and the adsorption ratio was mainly affected by ions. The adsorption ratio of algicide on $\mathrm{Pb}$ was higher than that of $\mathrm{Ni}$. The adsorption ratio of the $400 \mathrm{mg} \mathrm{L}^{-1}$ algicide was higher than that of the $550 \mathrm{mg} \mathrm{L}^{-1}$ algicide.

The isotherm adsorption model parameters of algicide on absorbing $\mathrm{Pb}$ and $\mathrm{Ni}$ are listed in Table 1. Comparisons of $\mathrm{R}^{2}$ demonstrated that the adsorption of heavy by algicide were all consistent with the two types of isothermal adsorption models. The maximum adsorption capacities were $38.21,35.81,32.80$ and $30.97 \mathrm{mg} / \mathrm{g}$ for the 400 and
$550 \mathrm{mg} \mathrm{L}^{-1}$ algicide for $\mathrm{Pb}$ and $\mathrm{Ni}$ in the Langmuir isothermal adsorption model, which was basically consistent with the results shown by the experiments. $n$ described the changing trends of the isotherms, and $n^{-1}<1$ suggested that the adsorptions of algicide on the two metals were easily absorbed in the Freundlich isothermal adsorption model.

Compared with chitosan, due to the loss of amino group during the glutaraldehyde cross-linking and adsorption of $\mathrm{SA}$, as well as the blocking function to some adsorption sites by the cross-linking reagent in the spatial structures, different degrees of decreases occurred in the adsorption capacity of the cross-linked products (Baroni et al. 2008; Ngah et al. 2002). However, the cross-linking of glutaraldehyde to chitosan is necessary. The powder chitosan changed into fine granular and steady structure with strong thermal stability. It could not be dissolved in acid medium, and the degree of swelling was also very small ( $\mathrm{Hu}$ and Zhu 2012). Algicide was produced by using the adsorption ability of the cross-linked chitosan to phenolic acids, and heavy metal ions and heavy metals in water were removed, achieving good results. These results were consistent with the high adsorption ability of glutaraldehyde cross-linked chitosan to metal previously shown in numerous investigations (Athena et al. 2007). The results on adsorption rate of algicide to low concentration of heavy metals showed that the adsorption rates of algicide to the two heavy metals $\mathrm{Pb}$ and $\mathrm{Ni}$ were high enough to remove low concentration heavy metals, which was also suitable for the low concentration of heavy metals in the surface water of the natural water (Chen et al. 2012). In addition, the toxicity of low concentrations of heavy metals to algae was smaller, and the heavy metals could not change or affect the outbreak of water bloom, so that 
Table 1 Langmuir and Freundlich isothermal adsorption model parameters of adsorption of $\mathrm{Pb}$ and $\mathrm{Ni}$ by algicide

\begin{tabular}{|c|c|c|c|c|c|c|c|}
\hline \multirow[t]{2}{*}{$\begin{array}{l}\text { Heavy metal/algicide } \\
\text { concentration } \mathrm{mg} \mathrm{g}^{-1}\end{array}$} & \multirow[t]{2}{*}{$\begin{array}{l}\text { Measured data } \\
Q_{\max } /\left(\mathrm{mg} \mathrm{g}^{-1}\right)\end{array}$} & \multicolumn{3}{|c|}{$\begin{array}{l}\text { Langmuir isothermal } \\
\text { adsorption model }\end{array}$} & \multicolumn{3}{|c|}{$\begin{array}{l}\text { Freundlich isothermal } \\
\text { adsorption model }\end{array}$} \\
\hline & & $Q_{\max } /\left(\mathrm{mg} \mathrm{g}^{-1}\right)$ & $b /\left(\mathrm{L} \mathrm{mg}^{-1}\right)$ & $R^{2}$ & $n^{-1}$ & $K$ & $R^{2}$ \\
\hline $\mathrm{Pb} / 400$ & 35.23 & 38.21 & 0.0443 & 0.9977 & 0.168 & 14.048 & 0.9947 \\
\hline $\mathrm{Pb} / 550$ & 33.58 & 35.81 & 0.0574 & 0.9985 & 0.143 & 15.448 & 0.9968 \\
\hline $\mathrm{Ni} / 400$ & 30.94 & 32.80 & 0.0617 & 0.9989 & 0.128 & 15.353 & 0.9980 \\
\hline $\mathrm{Ni} / 550$ & 29.58 & 30.97 & 0.0796 & 0.9993 & 0.107 & 16.486 & 0.9990 \\
\hline
\end{tabular}

low concentrations of heavy metals entered the algal cells and produced biological amplification. Therefore, the adsorption removal of low concentration of heavy metals is particularly important.

Removal capacity of algicide in algae solution to heavy metals

Concentration variations of the heavy metals $\mathrm{Ni}$ and $\mathrm{Pb}$ in the $\mathrm{CK}$ group without adding algicide and the groups treated with 400 and $550 \mathrm{mg} \mathrm{L}^{-1}$ algicide are shown in Fig. $4 a, b$, and the changes of chlorophyll a are demonstrated in Fig. 4c, d. The blank group was not treated with algicide. Heavy metals $\mathrm{Ni}$ and $\mathrm{Pb}$ were absorbed by $\mathrm{Mi}$ crocystis flos-aquae in the $\mathrm{CK}$ group, and the adsorption rates were 89.8 and $75.3 \%$ at 13 days. The adsorption rates increased with the increase of algae density. In the groups treated with 400 and $550 \mathrm{mg} \mathrm{L}^{-1}$ algicide, the density of algae was higher in the $400 \mathrm{mg} \mathrm{L}^{-1}$ group at 1 and 3 days, and the heavy metal ions adsorbed by algae cells were greater in number. Therefore, relatively low concentrations of heavy metals were exhibited. Several days later, the majority of the algal cells were destroyed by the released SA. Some dead cells of cyanobacteria may have autolyzed (Chen et al. 2006). Thus, heavy metal ions released by algae cells were probably absorbed by algicide. The adding dosage was high in the $550 \mathrm{mg} \mathrm{L}^{-1}$ group, and the adsorption rate was also correspondingly high, thus the concentration of heavy metals in the $400 \mathrm{mg} \mathrm{L}^{-1}$ group was higher than that of the $550 \mathrm{mg} \mathrm{L}^{-1}$ group. In the groups treated with 400 and $550 \mathrm{mg} \mathrm{L}^{-1}$ algicide, the adsorption rates of $\mathrm{Ni}$ reached 61.0 and $64.9 \%$ at 13 days, respectively, and the adsorption rates of $\mathrm{Pb}$ reached 71.2 and $72.5 \%$, respectively. In addition, the heavy metals $\mathrm{Ni}$ and $\mathrm{Pb}$ demonstrated inhibitory effects on the growth of microalgae. The inhibition rates reached 16.8 and $28.4 \%$ at 13 days, respectively. These results indicate that $\mathrm{Pb}$ showed relatively stronger toxicity on Microcystis flosaquae than $\mathrm{Ni}$. The results in the group of algicide showed that algicide and heavy metals exhibited synergy inhibition effects on algae. Compared with that of the algicide group, the inhibition rate increased by $10 \%$, as shown in Fig. 2e. The above results demonstrate that the algicide in SA can damage algae cells, and the heavy metal ions absorbed and released by algae cells are probably absorbed by crosslinked chitosan in algicide, thus blocking the enrichment of heavy metals in the food chains, thereby reducing harm caused by heavy metals.

The produced adsorption of chitosan to the heavy metal chelate is affected by the solution $\mathrm{pH}$ value, morphological changes of heavy metals, and deacetylation degree of chitosan (Guibal 2004). However, in the specific neutral environments in this experiment, the heavy metal adsorption of cross-linked chitosan was affected by the adsorbed SA, the metal ions in medium, algal cells and their released materials. (1) After adding 400 and $550 \mathrm{mg} \mathrm{L}^{-1}$ concentrations of algicide into the algae liquids, the release rates of $\mathrm{SA}$ in water at $48 \mathrm{~h}$ were 60 and $56 \%$, respectively. After the release of SA, the active groups were liberated and were thus able to chelate and absorb heavy metals. (2) The BG11 culture medium used in the experiments contained $\mathrm{Mn}, \mathrm{Cu}, \mathrm{Zn}, \mathrm{Fe}$ and other competitive metal ions, and chitosan exhibited high adsorption properties to these metal ions (Chen et al. 2009). Due to the competition of ions in reducing the adsorption capacity of chitosan for $\mathrm{Ni}$ and $\mathrm{Pb}$, the adsorption rate of algicide to the heavy metals in the algae solution was not as high as that in the pure water. At the same time, as demonstrated in Fig. $2 a, b$, the adsorption of chitosan on $\mathrm{Mn}, \mathrm{Cu}, \mathrm{Zn}, \mathrm{Fe}$ and other metal ions in the medium showed no effect on the growth of Microcystis flos-aquae, indicating that some metal ions in the medium were excessive and met the growing need for algae, and the adsorption capacity of algicide on these metal ions was not sufficient to inhibit the growth of Microcystis flos-aquae. (3) The main component of the blue-green algae cell wall was peptidoglycan, which could chelate a large amount of transition metal ions from aqueous solutions, and the viscous gelatinous sheath and extracellular polysaccharide had the adsorption capacity 

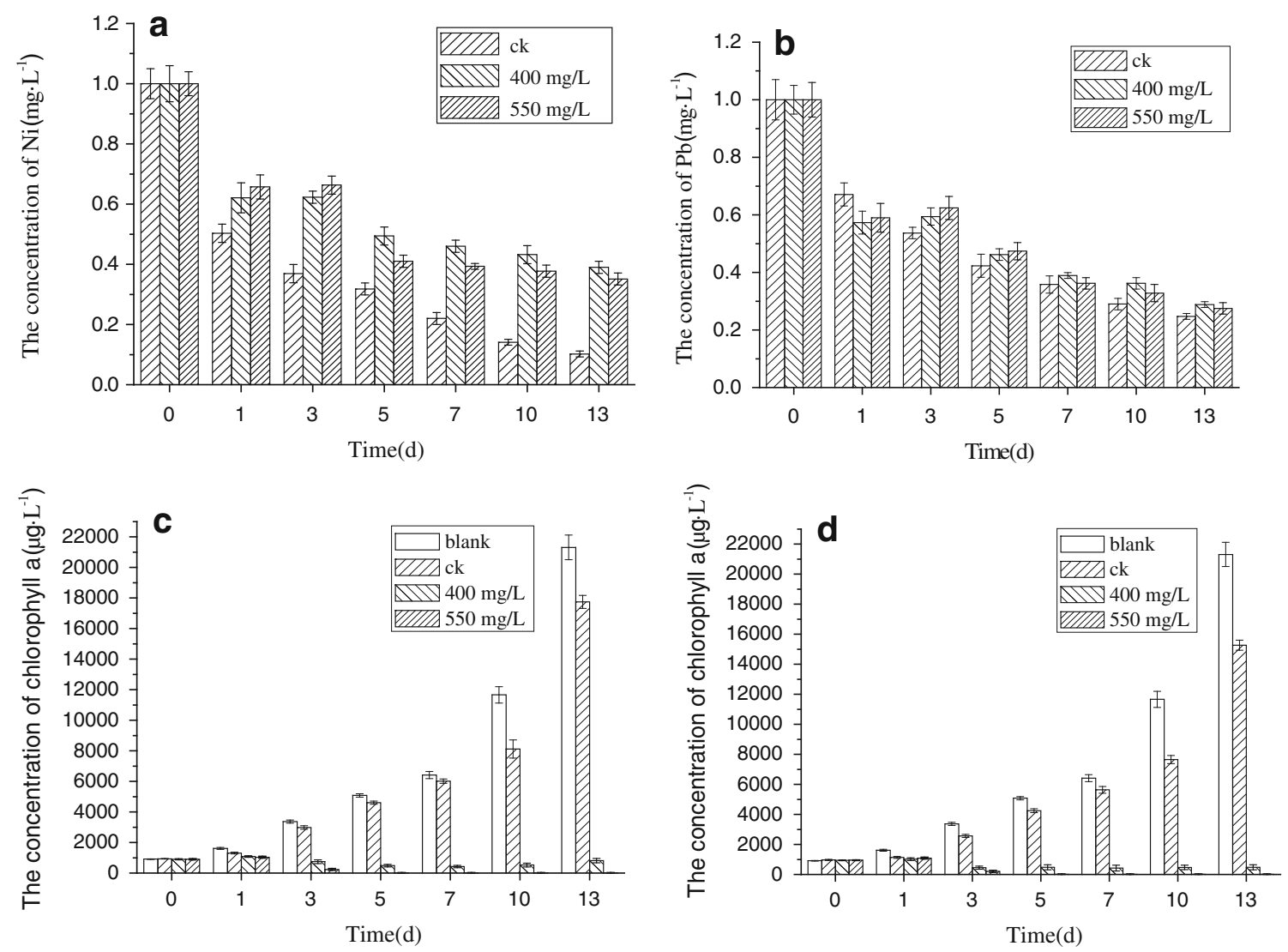

Fig. 4 Adsorption capacity of algicide on heavy metals $\mathrm{Ni}(\mathbf{a})$ and $\mathrm{Pb}(\mathbf{b})$ and effects of algicide on growth of Microcystis flos-aquae (c, d)

of metal ions. Metal ion binding sites were also present in the cells of blue-green algae, such as metal sulfur protein and poly phosphoric acid (Rangsayatorn et al. 2002). The damage ability of SA to algal cells can alter the cell structures, but the adsorption changes the shape variations of the heavy metals, thus causing some of the heavy metal ions to not be absorbed by the chitosan, and these ions may affect the determination results by permeating the filter membranes. In conclusion, various factors reduce the overall heavy metal removal ability of algae in this particular algae solution environments, but in the 400 and $550 \mathrm{mg} \mathrm{L}^{-1}$ added concentrations of algicide, the removal rate of $\mathrm{Pb}$ was higher than that of $\mathrm{Ni}$, which was consistent with the results of Tran et al. (2010), indicating that the heavy adsorption ability of the cross-linked chitosan did not change under the same affecting conditions.

In addition, compared with $\mathrm{Ni}, \mathrm{Pb}$ showed a higher toxicity. However, Ouyang et al. (2012) investigated and compared the effects of several heavy metals on chlorella toxicity, and the results showed that $\mathrm{Pb}$ did not cause any effect on Chlorella vulgaris. The reasons for this may be that the Microcystis flos-aquae used in the present study was the prokaryotic cyanobacteria, and the algae Chlorella vulgaris was eukaryotic algae. The different structure of the cell walls may have caused the different effects.

\section{Conclusion}

The absorption effect of the cross-linked chitosan for salicylic acid was good. The desorption of the prepared algicide was affected by the algicide dosage and desorption time. With the extension of time and increasing dosage of algicide, the quantity of the released SA increased gradually, and the sustained-release effect was good. The inhibitory efficiency of algae for Microcystis flos-aquae increased with the increased adding quantity of algicide. The higher the adding quantity of algicide was, the clearer the inhibitory effects of algicide were. The inhibition time of algicide was longer than that of the same content of SA adding directly, indicating that the cross-linked chitosan showed protective roles for SA and prevented simultaneous oxidation consumption from occurring. Algicide showed a high adsorption rate for low concentrations of heavy metals 
and demonstrated high adsorption proportion for high concentrations of heavy metals. Algicide was especially important for the adsorption and removal of low concentrations of heavy metals. Algicide released SA, thus destroying the algae cells and triggering the release of the absorbed heavy metal ions, which was most likely convenient for the adsorption and removal of heavy metals by algicide, and thus prevented the entering of food chains of heavy metals by algae, and produced biological enrichment.

Acknowledgments This research was supported by the National Natural Science Foundation of China (No. 20777021), Ministry of Education, Key Research Project of Science and Technology (No. 210253), and the Natural Science Foundation of Fujian Province of China (No. 2010J01043, D0610012).

\section{References}

Athena W, Merrill DH, David MG (2007) Metal complexation of chitosan and its glutaraldehyde cross-linked derivative. Carbohydr Res 342(9):1189-1201

Bailey SE, Olin TJ, Bricka RM, Adrian DD (1999) A review of potentially low-cost sorbents for heavy metals. Water Res 33(11):2469-2479

Baroni P, Vieira RS, Meneghetti E, da Silva MGC, Beppu MM (2008) Evaluation of batch adsorption of chromium ions on natural and crosslinked chitosan membranes. J Hazard Mater 152(3): $1155-1163$

Chang SC, Li CH, Lin JJ, Li YH, Lee MR (2014) Effective removal of Microcystis aeruginosaand microcystin-LR using nanosilicate platelets. Chemosphere 99:49-55

Chen SJ, ZhengWJ Yang F (2006) Study advances on heavy metals bio-absorbed by cyanobacteria. Marine Environ Sci 25(4):103-106

Chen AW, Yang CY, Chen CY, Chen CY, Chen CW (2009) The chemically crosslinked metal-complexed chitosans for comparative adsorptions of $\mathrm{Cu}(\mathrm{II}), \mathrm{Zn}(\mathrm{II}), \mathrm{Ni}$ (II) and $\mathrm{Pb}(\mathrm{II})$ ions in aqueous medium. J Hazard Mater 163(2-3):1068-1075

Chen K, Zhou YH, Zhang HJ (2012) Pollution evaluation of heavy metal element of water and surface sediment in the Dongchang Lake. Period Ocean Univ China 42(10):97-105

Fan W, Xu Z (2011) Biosorption of nickel ion by Chitosanimmobilized Brown Algae Laminaria japonica. Chem Biochem Eng Q 25(2):247-254

Guibal E (2004) Interactions of metal ions with chitosan-based sorbents: a review. Sep Purif Technol 38(1):43-74

Haddadchi GR, Gerivani Z (2009) Effects of phenolic extracts of canola (Brassica napuse L.) on germination and physiological responses of soybean (Glycin max L.) seedlings. Int J Plant Prod $3(1): 63-73$

Heinz WG. (2003) Phytoplankton Analyzer Phyto-Pam and PhytoWin Software V 1.45. Effeltrich, Germany

Hou DY, Feng J, Xie SL (2012) Toxic effects of nanoparticle $\mathrm{TiO}_{2}$ stress on Chara vulgaris L. Acta Scientiae Circumstantiae 32(6): 1481-1486

Hu HY, Zhu H (2012) Adsorption of heavy metal ions by chitosan and its derivatives. Prog Chem 24(11):2212-2222

Imran A, Mohd A, Tabrez AK (2012) Low cost adsorbents for the removal of organic pollutants from wastewater. J Environ Manag $113: 170-183$
Jeon C, Park KH (2005) Adsorption and desorption characteristics of mercury(II) ions using aminated chitosan bead. Water Res 39:3938-3944

Ji JG, Hao SL, Wu DJ, Liu L, Chen JD, Xu Y (2011) Preparation, characterization and in vitro release of chitosan nanoparticles loaded with gentamicin and salicylic acid. Carbohydr Polym 85(4):803-808

Jiang D, Huang LF, Lin SQ, Li YX (2010) Allelopathic effects of euhalophyte Salicornia bigelovii on marine alga Skeletonema costatum. Allelopathy 25(1):163-172

Jiang J, Li L, Li HP, Li FL (2012) Biosorption of lead(II) and cadmium(II) from aqueous solution by Chlorella pyrenoidsa and its influential factors. Acta Ecologica Sinica 32(7):1995-2003

Kocak N, Sahin M, Arslan G, Ucan HI (2012) Synthesis of crosslinked chitosan possessing schiff base and its use in metal removal. J Inorg Organomet Polym Mater 22(1):166-177

Kovacik J, Klejdus B, Hedbavny J, Backor M (2010) Effect of copper and salicylic acid on phenolic metabolites and free amino acids in Scenedesmus quadricauda(Chlorophyceae). Plant Sci 178(3):307-311

Kumar MNVR (2000) A review of chitin and chitosan applications. React Funct Polym 46(1):1-27

Li ZH, Wang Q, Ruan X, Pan CD, Jiang D (2010) Phenolics and plant allelopathy. Molecules 15(12):8933-8952

Ngah WSW, Endud CS, Mayanar R (2002) Removal of copper(II) ions from aqueous solution onto chitosan and cross-linked chitosan beads[J]. React Funct Polym 50(2):181-190

Nikulina A, Dullo WC (2009) Eutrophication and heavy metal pollution in the Flensburg Fjord: a reassessment after 30 years. Mar Pollut Bull 58(6):905-915

Ouyang HL, Kong XZ, Qin N, He W, He QS, Wang Y, Wang R, Xu FL (2012) Effects of five heavy metals at sub-lethal concentrations on the growth and photosynthesis of Chlorella vulgaris. Chin Sci Bull 57(10):785-793

Poulson KL, Sieg RD, Prince EK, Kubanek J (2010) Allelopathic compounds of a red tide dinoflagellate have species-specific and context-dependent impacts on phytoplankton. Mar Ecol Prog Ser 416:69-78

Rangsayatorn N, Upatham ES, Kruatrachue M, Pokethitiyook P, Lanza GR (2002) Phytoremediation potential of Spirulina (Arthrospira) platensis: biosorption and toxicity studies of cadmium. Environ Pollut 119(1):45-53

Tran HV, Tran LD, Nguyen TN (2010) Preparation of chitosan/ magnetite composite beads and their application for removal of $\mathrm{Pb}$ (II) and $\mathrm{Ni}(\mathrm{II})$ from aqueous solution. Mater Sci Eng C Mater Biol Appl 30(2):304-310

Vidhyavathi R, Sarada R (2011) Effect of salicylic acid and methyl jasmonate on antioxidant systems of Haematococcus pluvialis. Acta Physiol Plant 33(3):1043-1049

Wei XH, Niu YP, Xu YY, Du YZ, Hu FQ, Yuan H (2010) Salicylic acid-grafted chitosan oligosaccharide nanoparticle for paclitaxel delivery. J Bioact Compat Polym 25(3):319-335

Wu C, Chang XX, Dong HJ, Li DF, Liu JY (2008) Allelopathic inhibitory effect of Myriophyllum aquaticum (Vell.) Verdc. on Microcystis aeruginosa and its physiological mechanism. Acta Ecologica Sinica 28(6):2595-2603

Wu FC, Tseng RL, Juang RS (2010) A review and experimental verification of using chitosan and its derivatives as adsorbents for selected heavy metals. J Environ Manag 91(4):798-806

Xin MH, Li MC, Zhang XS, Gu DD, Deng J (2009) Preparation of chitosan microspheres modified by $\alpha$-ketoglutaric acid and their adsorption property. Polym Mater Sci Eng 25(1):133-136

Yang H, Yuan B, Lu YB, Cheng RS (2008) Preparation of magnetic $\mathrm{PAA} /$ chitosan microspheres and its application in wastewater treatment. Scientia Sinica Chimica 38(9):755-761 
Yang F, Liu HJ, Qu JH, Chen JP (2011) Preparation and characterization of chitosan encapsulated Sargassum sp. biosorbent for nickel ions sorption. Bioresour Technol 102:2821-2828

You LX, Wang P, Kong CH (2011) The levels of jasmonic acid and salicylic acid in a rice-barnyardgrass coexistence system and their relation to rice allelochemicals. Biochem Syst Ecol 39(4-6):491-497
Zhang TT, Wu AP, He M, Chen CP, Nie LW (2007) The allelopathy and its mechanism of phenolic acids on water-bloom algae. China Environ Sci 27(4):472-476

Zhen HB, Hu YY, Cheng JH (2011) Adsorption of $\mathrm{Cu}^{2+}, \mathrm{Ni}^{2+}$ and $\mathrm{Cd}^{2+}$ by chitosan cross-linked zeolite beads. Acta Scientiae Circumstantiae 31(7):1369-1376 